\title{
Information, Self-Reference and Observation Theory in the Context of Social Sciences Epistemology
}

\author{
Juan Miguel Aguado \\ School of Information and Communication Studies, University of Murcia (Spain); E-mail: jmaguado@um.es
}

\begin{abstract}
By attempting to fix an observable magnitude, the concept of information involves a cognitive model that enables a double ontological rupture: between subject and world, on one side, and between cognition and action, on the other side. A genealogical approach to information as a simultaneously epistemological and cognitive crossroad highlights the centrality of observation theory in the resolution of its contradictions. The recursive nature of observation inherent to informational logics makes constructivist assumptions especially relevant as a key contribution for an epistemological revision of the ideas of information and communication.
\end{abstract}

Keywords: Information, observation, constructivism, cognition, self-reference

$\mathrm{T}$ he central nature of the concept of information is not only found in the fact that it constitutes the cornerstone of a contemporary mythology through which society understands itself. The idea of information involves a theory of cognition in the sense of a conception of the subjectworld relationship that operates as a propelling force of such mythology and that, not causally, joins a long philosophical tradition about the nature of knowledge as an intervention oriented representation (Hacking, 1995; 1996).

That central nature constitutes a good example of an epistemological paradox: if initially the notion of information seeks to be erected as a scientific object in the classic sense - that is, an ontologically selfcontained object-, it is on the basis of its semantic coherence with the cognitive model from which it emerges (and the one it supports) that it operates as a universal explicative metaphor. Consequently, contrary to the classic epistemological approaches that involve a strict separation between the observed phenomena and the conceptual frameworks contributing to explain them, the contemporary drifts of the idea of information raise a specially symptomatic case of the thesis that Duhem and Quine named with the meaningful title subdetermination of theories by observation (Schuster, 1996) ${ }^{1}$.

From a somehow ironic perspective, Heinz von Foerster (1969) has referred to the case with the expression 'pathological semantics' ('antropomorfization' processes by which the relationships are reversed between the terms explicative and explained of the metaphors that correlate the experience of the observer and the observed processes). The very conception of memory as a 'capture, registration and retrieval of information' process constitutes, in the words of the author cited, a good sample of pathological semantics. Dupuy (1994) has likewise attracted attention in noticing that the concept of model as an explicative strategy in the

\footnotetext{
1 The thesis of subdetermination of theories by observation disqualifies the isomorphism between theories as explicative artefacts and reality as an explained phenomenon. In agreement with the proposal by Quine and Duhem a theory can only be tested empirically as far as the observed facts carry an interpretive key of themselves. The basis of the theory goes back to Quine's reflection about the theoretical weight of observation and about the search for adjustment between theoretical terms and observational terms as a part of the scientific process (Schuster, 1996, pp. 10-14). Ultimately, it points to the circular problem of the act of observation as a point of inclusion of the observer into the observed.
} 
development of cognitive sciences had moved its semantic gravity centre from 'that which imitates' to 'that which is imitated' (for instance in the modeling relationship between brain and computers). Therefore, our initial argument departs from considering the informational paradigm as the result of a technical operativity which, although originally thought of as an explicative construct, becomes an explained phenomenon on the basis of its instrumental coherence (cf. Aguado, 2003, p. 200).

On the following pages different ideas are proposed: first, a brief genealogical characterisation of the concept of information in the shape of a journey around the main critical lines regarding the classic informational model emanated from the interdisciplinary context of cognitive sciences. We find three recurrent epistemological problems in the background of that genealogy, which are especially sensitive to social sciences: the problem of the primary ontological foundation, the problem of the fracture between subject and object and the problem of observational reflexivity. Although they are closely related issues, we will be dealing specifically with the issue of observational reflexivity, since it is from here that the constructivist perspective puts the salt of its logical coherence to the informational wound: information is thought of as both a cognitive and an epistemological dilemma precisely because it is an observational problem.

We are not, however, dealing here with a classic observational problem, concerned with methodological formalization. More than anything, information makes us face a problem of recursiveness: it is both an observed phenomenon and a phenomenon of observation from which the observer is constituted. Hence its crossroads nature and the relevance of those approaches that urge to the awareness of the essentially reflexive condition of observation (from the second order cybernetics outlined by Heinz von Foerster and developed in the theory of autopoietic systems by Maturana and Varela to the systemic constructivism by von Glasersfeld or Luhmann).
In the last part general lines are proposed for a recursive comprehension of the pair information/knowledge departing from the observational logics by Spencer-Brown (1979) which, due to its articulation about the correspondence between form and structure, is outlined as essentially informational logics.

\section{Information as a trace of Nature}

The idea of information as external processable data is based on a mechanistic tradition of the conception of knowledge which is closely related to a transparent conception of observation as a formalinstrumental procedure. Throughout the XIX century the development of mechanic devices $^{2}$ that embodied calculation processes conceived as expressions of the human intellect enabled the extension of the principle of knowledge as representation (what can be represented can be known) to the reproduction field (what can be reproduced can be known). This way the door was open to a reflexive movement of knowledge about itself which later on would establish the leit motif of the cognitivist paradigm: if it can be represented, it can be reproduced (and vice versa). The formalization of representation is conceived in this framework as mechanisation of knowledge and consequently, the latter becomes inherently reproducible.

The symbolic space of western tradition around this instrumental-representational

\footnotetext{
${ }^{2}$ The history of the production of mechanical-logical mechanisms is not circumscribed obviously to the XIX century. From the mechanism of Antikytera ( $2^{\text {nd }}$ century B.C.) or Renaissance's logical automatons to Lull's Ars Magna or the identity between thought and logic expressed by Boole in the theoretical field, the mechanical reproduction of calculus and other logical functions posed as a mechanisation of thought has dominated myth and experiment equally. In another text (Cfr. Aguado, 2000) we have gone through the history of automata understood as embodiments of the epistemological link between reproduction and knowledge in a double evolutionary trajectory: automatons of action (those mechanisms designed for the reproduction of instrumental actions) and automatons of cognition (those mechanisms designed for the reproduction of cognitive actions). Certainly, following Hacking (1996) it would seem more appropriate in this context to distinguish between intervention automata (mechanisation of action upon the world) and representation automata (mechanisation of knowledge).
} 
conception of knowledge - of the mind as a mirror of nature, following Rorty (1996) - is built in the field of two essential coordinates: the abscissa delimited by the pair subject/object (the one who knows and what is known) and the ordinate delimited by the pair knowledge/action (Aguado, 2001). The characteristic shape of such symbolic space has been fracture and discontinuity. On the one hand, the representational conception of knowledge marks the fracture between knowledge and action in terms of the distinction between representation and intervention (Hacking, 1996), and about this fracture, the incommensurability between subject and object is outlined in the shape of a recursive paradox: the representer represented on the basis of the representation of the representation. The cornerstone of this recursive observational paradox is the syntax of cognition, and it is precisely at this point that the idea of information comes to play the central role mentioned before.

Boole's algebra and Shannon and Weaver's Mathematical Theory of Communication, came to allow experimental status to something that up to then had only been a hypothesis: thinking is computing, computing is representing. If at the end of the XIX century the mathematician George Boole had consolidated the mechanization of thought on the basis of its identity with logic (thinking means articulating formally structured propositions), the mechanization of representation was consolidated with Shannon's contribution in the middle of $X X$ century: the Boolean all or nothing binary logics could operate in electrical circuits (connection/disconnection) (on/off) in such a way that it was possible to test the automatic character of the algorithmical or propositional thought (Dupuy, 1994).

Apparently, the encounter between Boole's restricted algebra and the Mathematical Theory of Communication came to solve an ancestral problem: the establishment of a representational magnitude that would permit the articulation of a syntax of cognition independently from the representer. The dilemma, which had been philosophical up to then, about the subject's access to the world acquired thus the status of experiment: if it was possible to establish a representational syntax independent from the representer, then it was possible, both to guarantee the access to the object (representing is reproducing), and also to guarantee the access to the subject (reproducing the representer by means of formalizing its action of representing). However, that proposal demanded the requirement of a radical detachment between representation and meaning or rather the approach to meaning in terms of syntax understood as a form of order.

The consolidation of a materialistic concept of information (Shannon and Wever, 1949) equipped with an epistemic status similar to the one of energy or mass (Shannon, 1972) came to fulfill that demand in the confluence of logics (originally Boole's restricted algebra), the engineering of transmissions (Hartley, 1928) and thermodynamics (Szilard, 1929; Brillouin, 1965)-, combining the syntactical-logical power with the linking (somehow also syntactical) of information to the production of order. If knowledge as representation involved the identification of order as a condition of reproducibility, information was presented in this context as a universal magnitude of order in the sense of a kind of 'intimate structure of the universe'.

Transformed into a measure of the knowledgeability (as much as representability) of the world leaving out the condition and the action of the knowing subject, information circumscribes communication to the transmission of (the reproduction of) order and delimits cognition as "the processing of information" (that is, its capture and/or production, its articulation, its transmission) by means of the manipulation, through specific rules, of physical elements (symbols) whose operability are defined precisely by its form. That is the link between the secular tradition of the mind as a mirror of reality and the so-called cognitivist hypothesis (Varela, 1996, pp. 43-44), whose validity permits, for example, to describe the mind and the computer as "processing systems of external information". Knowledge here keeps its character of mirror of Nature (Rorty, 1983), but now, inasmuch as the essential substance of Nature is information, 
the mirror no longer reflects images, laws, causes or functions, but rather, ordered sets of bits, that is, the order of what is reflected:

"Information exists. It does not need to be perceived to exist. It does not need to be understood to exist. It requires no intelligence to interpret it. It does not have to have meaning to exist. It exists. [...] The most fundamental aspect of information is not a construction of human mind, but a basic property of the Universe. [...] Information is a quantity which may be altered from one form to another. Information is a quantity that can be transferred from one system to another" (Stonier, 1990, pp. 21-26)

Conceived that way, as von Foerster (1991, p. 60) reminds, information is susceptible to be "processed", "retrieved", "stored", "chopped", etc. as if it were hamburger meat", in such a way that the operator of knowledge is left with a similar role to that of the butcher's: obtain, process and distribute. Leaving aside humour, criticisms to the cognitivist model which involves the binomial information-cognition in the model of an industrial assembly line (in the sense that it breaks the process in functional moments and separates the subject from the production of knowledge) have hardly limited its implantation as universal mythology. Something similar happened in the first half of the XX century to the psychoanalytical theory of the unconscious: the diffusion in everyday life of an interpretative model emanated from science does not depend, finally, on its precision or accuracy, its internal coherence or its falsability, but rather on its functional and semantic coherence with the sociocultural environment in which it is developed.

\section{Avatars of information}

The generalization in everyday use of the reified idea of information must not, however, hide the complexity and richness of the debate it has produced. Much of this debate emanates from the contradictions inherent to the Shannonian formulation, summarized in the last two sentences of the following wellknown quotation:

"The fundamental problem of
communication is that of reproducing at
one point either exactly or
approximately a message selected at
another point. Frequently the messages
have meaning; that is they refer to or
are correlated according to some
system with certain physical or
conceptual entities. These semantic
aspects of communication are irrelevant
to the engineering problem. The
significant aspect is that they are
selected from a set of possible
messages" (Shannon y Weaver, 1949,
pp. 31-32)

As Bateson (1985, p. 413) rightly pointed out, the engineers and mathematicians believe that they can avoid the complexities and difficulties introduced into communication theory by the concept of 'Meaning' reducing the matter to the syntactical level and building the concept of information from a theory of the signal (von Foerster, 1991,60). But the idea of signal is only apparently aseptic, only apparently syntactical. The signal refers to a difference that is 'out there', but that 'something' which is difference is distinguished by someone. The distinction is presupposed by Shannon and Weaver as a selection (see Qvortrup, 1993). The fact that information is defined as the probability of selection involves the observer in at least two aspects: one, probability implies expectation and context of use; and two, the selection is only conceivable on the basis of the assumption of someone who selects. Both assumptions involve implicit semantics as the horizon of meaning (Brier, 1992).

Apart from this, the development of the concept of information as a measure of order that constitutes its fundamental link with universal magnitudes (such as mass or energy) presupposes the observational act as well. In Shannon and Weaver's theory, both information and noise depend on variety. If redundance is defined according to the "adjustment" between variety and the number of elements, information and noise are expressed in direct proportion to variety. In other words, information and noise depend 
on the number of elements different from one another. Neither of them can be defined in larger quantities than those allowed by the amount of variety (Ashby, 1977, p. 238). In fact, as Ashby poses,

"It must be noticed that noise is in no intrinsic way distinguishable from any other form of variety. Only when some recipient is given, who will state which of the two is important to him, is a distinction between message and noise possible" (Ibid, p. 256)

The issue of the distinction between information and noise brings us definitely to the problem of observation. It seems implicit in Ashby's words that order is the cognitive contribution of the observer that makes it possible to conceive the difference between information and noise: order, as a Peircean sign, it is so for someone in a certain circumstance. The resultant paradox is that information is proposed as a universal measure of order for a system whose activity of selection (the one information depends on) involves a local order, coherent with its structure and operations. From the point of view of communication (understood as 'transmission' of information), there has to be a correspondence between the orders of selection of those observing systems involved and, therefore, there has to be an operational and structural correspondence between them (von Foerster, 1991, p. 75).

The epistemological contradictions of information ultimately refer to its condition as a code of difference. Consequently, it is primarily an observational problem, a problem of the management of differences. In this sense, and following partially Qvortrup's classification (1993), it is possible to outline at least three differentiated positions throughout the contemporary debate about the epistemological status of information:

(a) The objectivist position, according to what has been posed before, considers information as an ontologically self-sufficient magnitude of Nature. In this case, the information is an external difference to the observer and independent from him. Without resorting to Stonier's ontological exaltation mentioned above, Wiener's words suffice to illustrate the common denominator of this approach and its cognitive-communicational derivations:

"Information is a name for the content of what is exchanged with the outer world as we adjust to it, and make our adjustment felt upon it. The process of receiving and using information is the process of our living effectively within that environment. To live effectively is to live with the adequate information" (Wiener, 1954, p. 18)

(b) The constructivist position introduces in the concept of information the observational instance as a result of the systematic reflection about the contradictions pointed out in the objectivist approach. The development of the second-order cybernetics $^{3}$ placed self-reference in a privileged position within the operations of the cognitive system, rejecting the conception of the informational flow in terms of transmission of objects. The constructivist shift established thus two complementary options: either (b.1) to revise the concept of information, so that it became coherent with an idea of communication understood as a behavioural coupling between two interacting systems, or (b.2) establish the hypothesis that the environment only exists for the system as a product of its own creation. The one we call 'constructivist position' corresponds to the first option (b.1), while the one we will give the name of 'radical constructivism' will emerge from the development of the second hypothesis (b.2).

The first option, derived from the incorporation of the observational reflexivity, compelled thus the consideration that communication did not depend so much on what 'the environment gave the system' but rather on what happened with the system in its interaction with the environment or with another system (Maturana and Varela, 1996,

\footnotetext{
${ }^{3}$ Second order cybernetics is concerned with the study of systems with circular causality whose operation is based on self-reference. Unlike classic cybernetics, which deals with externally observed systems, second order cybernetics deals with observing systems or systems that are capable of observation, i.e. systems that produce and manage the differences from which they are constituted as such (von Foerster, 1981).
} 
p. 169). Thus information ceased to be a 'capturable' external difference and came to be conceived as a difference in the environment linked to an operational change (a difference) in the system. The Batesonian definition of information as the difference that makes a difference (Bateson, 1985; 1991) summarises the conception of communication as operational coupling and in a way that advances the second constructivist hypothesis. In fact, for Bateson the difference is an observational operation that emanates from the encounter between the perceptive structure of the system and the world as it is presented to it. Implicitly the difference is neither in the world nor in the observer, but in the encounter between them, but also implicitly (b.2) the world can only be for the observing system depending on what it is (that is, the environment is part of the observing system inasmuch as its operational structure presupposes it). Consequently, in the end the difference is defined as a 'mental' issue $^{4}$.

(c) The radical constructivist position introduces, thus, a differential note with respect to Bateson's definition. Paraphrasing the famous sentence, from this perspective information would appear rather as the difference that finds a difference (Qvortrup, 1993). In fact, this implies an elimination of the conductist substratum that remained in Bateson's formulation, in the sense that it made it possible to glimpse a cause-effect coordination between the difference in the environment and the difference in the

\footnotetext{
${ }^{4}$ The connection between Batesons' epistemological presuppositions and the Kantian dilemma of the noumenon (Das Ding an Sich) seems relevant here: "Clearly there are in the mind no objects nor events - no pigs, no coconut palms and no mothers-. The mind contains only transforms, percepts, etc [....]. The explanatory world of substance can invoke no differences and no ideas but only forces and impacts. And, per contra, the world of form and of communication invokes no things, forces or impacts but only differences and ideas" (Bateson, 1991, p. 271). The turn from an exogenous perspective of information to an endogenous perspective highlights here its complementarity with the foundational conception of symbolic interactionalism (Mead, 1972) at least in three aspects: the centrality of 'internal behaviours' in the communicative coordination, reflexivity as a characteristic of the production of the subject and, finally, the symbol as a mediation tool in the production of the world.
}

observing system. The consideration that the environment exists for the system depending on its operational structure obliged to restrict the functional determinism of the cause-effect connection in the system-environment encounter.

This view of information as an endogenous emergence of the operational coupling implies the conception of selection not in the terms of a designation or a 'pointing at' with respect to something external, but as a restriction of the system operation itself. In other words, the system does not select differences of the environment; the system is in itself a selection of the differences in the environment ${ }^{5}$. As in the previous case, the premise refers to a double hypothesis: one (c.1), the consideration, in the case of selforganising systems (like living systems) of the set system-environment as an inseparable whole for the external observer; and two, (c.2) the consideration of observing systems as operationally closed systems ${ }^{6}$. The former line of reflection (c.1) is the one developed by von Foerster (especially in von Foerster, 1981), the latter (c.2) constitutes the essence of the autopoietic systems theory developed by Maturana and Varela (1980, 1996 and Varela, 1979, 1996).

In his article Notes on an Epistemology for Living Things, published in 1972, Heinz von Foerster (1991:65-78) outlines the following propositional chain: (1) The environment is experienced as if it was the residence of objects, stationary, moving or changing; (2) The logical properties of "invariance" and

\footnotetext{
${ }^{5}$ In this sense Luhmann defines information as an event that selects system states. The interaction with the environment is only possible via structures that limit and pre select the possibilities. Information presupposes structure but it is not a structure in itself, rather it is an event which updates the use of structures (Luhmann, 1991, pp. 83-84).

${ }^{6}$ Both hypotheses presuppose identity between living systems, self-organised systems and observing systems (von Foerster, 1991, p. 40; Maturana and Varela, 1980, p. 32). An operationally closed system is that whose operations constitute its domain of existence (in philosophical terms, that for which 'to be is to exist'). Autopoietic systems are by definition operationally closed: their operations configure the domain in which they become themselves as organisational units. Operational closure presupposes and is constituted upon self-reflexivity (where system is the horizon of the operations of the system).
} 
"change" belong to the representations, not to the objects; (3) Objects and events are not primitive representations. They are representations of relations; in such a way that (4) the environment is the representation of the relations between "objects" and "events" and (5) a living organism is a third order relater (operation of relations between relations of relations) from which the differentiation between system and environment constitutes an emergence from that operation of relations:

"Let be $D^{*}$ the terminal representation made by an organism $\Omega^{*}$, and let it be observed by an organism $\Omega$; let $\Omega$ 's internal representation of this description be $D\left(\Omega, D^{*}\right)$; and, finally, let $\Omega$ 's internal representation of his environment be $E(\Omega, E)$. [...] The domain of relationships between $D$ and $E$ which are computable by $\Omega$ represents the "information" gained by $\Omega$ from watching $\Omega^{*}$ :

$$
\begin{aligned}
& \operatorname{Inf}\left(\Omega, D^{*}\right) \equiv \text { Domain Rel } \mu(D, E) \\
& (\mu=1,2,3, \ldots m)
\end{aligned}
$$

The logarithm (base 2) of the number $m$ of relationships Rel $\mu$ computable by $\Omega$ (or the negative mean value of the logarithmic probabilities of its occurrence $<\log _{2} p_{i}>=\Sigma p_{i} \log _{2} p_{i} ; i=$ $1 \rightarrow m$ ) is the "amount of information, $H^{\prime \prime}$ of the description $D^{*}$ with respect to $\Omega$ :

$$
H\left(D^{*}, \Omega\right)=\log _{2} m
$$

(or $\left.H\left(D^{*}, \Omega\right)=-\Sigma_{i} \log _{2} p_{i}\right)$ ) (Von Foerster, 1981, p. 78)

In such a way that both the descriptive approach to the concept of information (Inf) and the probabilistic expression of the amount of information $(H)$ prove to be relative concepts (c.1), being thus impossible to affirm that the environment "contains" information, and even less that it is "able" somehow to "transmit it" to the system. The corollary presents somehow solipsist notes that should be made more precise ${ }^{7}$. "The

\footnotetext{
${ }^{7}$ Von Foerster himself responds to the eventual imputation of solipsism linking the idea of communication
}

environment so as we observe it, is our construction", concludes von Foerster (1981, p. 41). Something similar happens with Varela's affirmation (1979, p. 45): «Information, sensu stricto, does not exist». It is important, as Qvortrup (1993) recommends, to consider the appreciations "in the way we observe it" and "in strict sense" that modalise each of the two sentences. Both appreciations refer to the recursive nature of observation. In von Foerster's terms, both precisions remind us that observations cannot be made without an observer, or as Varela points out:

"The fact is that information does not exist independent of a context of organization that generates a cognitive domain, from which an observer community can describe certain elements as informational and symbolic" (Varela, 1981, p. 45)

From the perspective of autopoietic systems $^{8}$ (c.2), the operational closure of the observing system makes a logical requirement from that endogenous conception of information:
"Autopoietic systems do not have inputs or outputs. They can be

to the theory of observation. On the basis of the principle of logic relativity (which characterises observation as a self-inclusive operation) and the endogenous conception of information, it becomes necessary to admit that "amongst the internal representations of the computation of objects $\operatorname{Obj}\left(x_{i}\right)$ within one organism $\Omega$ may be a representation Obj $\left(\Omega^{*}\right)$ of another organism $\Omega^{*}$. Conversely, we may have in $\Omega^{*}$ a representation $\operatorname{Obj}(\Omega)$ which computes $\Omega$ " (von Foerster, 1991, p. 73). When taking into account two cognitive reciprocally observable operators, the representations should be recursive in $\Omega$ and $\Omega^{*}$ respectively. Thus following von Foerster (Ibid.), in the case of the organism $\Omega$ we have: $O b j^{(n)}\left(\Omega^{\star(n-1)}\right.$ $\left.\left(O b j^{*(n-1)}\left(\Omega^{(n-2)}\left(O b_{j}^{(n-2)}\left(\ldots \Omega^{*}\right)\right)\right)\right)\right)$. The idea of communication conceived on the basis of the relativity principle and the closure between operators and operands strongly reminds the Mead's principle of the 'capacity to adopt the other's point of view' as a prerequisite of the complementary construction between self and other (Mead, 1972).

${ }^{8}$ Maturana (1996, p. 130) defines the autopoietic system as "composite unity whose organization can be described as a closed network of productions of components that through their interactions constitute the network of productions that produce them and specify its extension by constituting its boundaries in their domain of existence". 
perturbated by independent events and undergo internal structural changes which compensate these perturbations" (Maturana and Varela, 1980, p. 81)

As a consequence, what is normally perceived as interaction (in the sense of an exchange of information) is understood here as a behavioural coupling of operationally closed systems that perturbate each other (Qvortrup, 1993). This involves no longer a difference as cause of a difference, which presupposes a certain conmensurability between system and environment (or, in other words, an ontologization of the difference between both). It rather involves independent changes (as part of systems' structural drift) that couple becoming thus part of systems' horizon of operations and, as such, become meaningful differences. Rather than being produced or made, differences, in that case, are found by the system.

"In the context of the autopoietical reproduction the environment exists as irritation, disturbance, noise, and it only becomes meaningful when it can be related to the system's decision-making connections. This is only the case when the system can understand which difference it makes for its decisionactivity when the environment changes or doesn't change in one or the other respect. Such a difference which exists for the system in the environment and which for the system may imply a difference for the system itself, i.e. a different decision, in accordance with Gregory Bateson we would call information. As 'difference that makes a difference' information is always the system's own product, an aspect of the processing of decision and not a fact in the environment which exists independently of observation and evaluation. On the other hand the system cannot freely create information as its own product or let it be. The system is continuously perturbated by the environment, and with its decisionnetwork it seeks out perturbations so as to transform them into information and to use them as a guide for decision- making" (Luhmann cit. in Qvortrup, 1993)

In the end, the two constructivist perspectives considered here link the observational problems of information to a conception of cognition that, inasmuch as it is assumed as part of its own condition of observation, becomes necessarily a kind of epistemology 9 . In other words, for the constructivist perspective, cognition and epistemology overlap each other in the same operative principle:

"There is an external world which already follows from the fact that understanding can be made as a selfcontained operation; however, we do not have any direct access to the world. Understanding cannot reach the outside world without understanding. In other words, understanding is understanding as self-referential process" (Luhmann, 1990a, p. 33)

That self-referential proposal of cognition articulated upon an endogenous conception of information forces to attend to the biological principles implicit in observational logics and poses, in the end, a radical revision of the concept of communication.

\section{Observation, Cognition and Communication}

Spencer-Brown (1979) begins his Laws of Form that way: Draw a distinction. The distinction establishes the observing act by which a boundary is constituted, dividing space into two subspaces, two complementary delimited continents. The boundary hides a double-fronted complexity: simultaneously joins and separates, refers and differs. It is at the same time condition of possibility and limit, condition of relation and insulator, condition of process and state. The boundary is the prerequisite for the cognitive

\footnotetext{
9 "In the very moment we stop considering that the notions that we use are a property or an attribute of the observed system and we come to conceive them as an emergent product of the interaction between ourselves and the observed system [...] we shift from ontology to epistemology, from the observed systems to our knowledge of them" (Pakman, cit. in von Foerster, 1991, p. 103)
} 
production of a world: it organises a whole topology of perception on the basis of an ontology of the distinction. However, the distinction does not presuppose the difference; it articulates it, making the difference possible. There is no space (limited by difference) before the distinction. Distinction is perfect continence (lbid.).

Nevertheless, the topology of perception in which the fracture of space is organised is not yet a topology of meaning. To complete the observation cycle it is essential to draw an indication, the mark of the difference onto one of the sides of the distinction. On the space differentiated upon the distinction, it is possible to establish a topology of meaning, or in other words, it is possible to name the world produced.

If knowledge is an organizational extension of observation (Varela, 1980), it seems essential to get rid of the anthropocentrical attributes of the idea of knowledge in order to understand its organizational nature. Knowledge is, in general terms, the substantiation (favoured by an intellectual tradition focused on accumulation and, consequently, needing its materialization) of a characteristic process of living systems. According to Maturana and Varela (1996), we mean by knowledge, in a global and first sense, the structural coupling (or rather, the ontogenical co-dependence) between two living units or between a living unit and its environment. In this sense, the ideas of communication and knowledge are joined in the notion of co-ontogeny proposed by the mentioned authors (Ibid.), correlative, in its turn, of a wide concept of life.

\section{"The fact of living - of keeping continuously the structural coupling as a living being- is knowing in the field of existence. Aphoristically: living is knowing (living is effective action in the fact of existing as a living being)" (Varela, 1996, p. 149)}

In this existential living/knowing circle, the antropocentred conception of knowledge constitutes a variant characterized, further than the biological determinants, but in operational coherence with them, by the presence of three organizational poles: society, language and self-consciousness.
According to Maturana and Varela's deffinition, we assume the delimitation of the term cognition as anthropologically decentred knowledge, while according to the tradition mostly present in human sciences we reserve the term knowledge for those anthropocentric cognitive processes. If cognition is expressed in the emergence of operational coherences that constitute domains of existence, knowledge is substantiated in operational coherences with a socio-linguistic base that constitute domains of reality ${ }^{10}$.

The relation between knowledge and cognition, accordingly, is constituted in double contingency. Knowledge emerges on the base of the cognitive processes carried out in the threefold context society-languageself consciousness; but at the same time, inasmuch as they are linguistically and socially centered, we have no option but considering cognition on the basis of knowledge or, in other words, our domains of reality, existence and cognition are respectively overlapped: "Everything is included in meaning, but meaning is an emergence from that everything" (Morin, 1992, p. 173).

Consequently, knowledge can be understood, in general terms, as the building process of subject/world relations, where "world" refers to the non-subject, i.e., all that remains on the other side of the distinction that makes the subject emerge. The preference for the use of "world" instead of "object" comes from the consideration of the specificity of the subject/object pair as a

\footnotetext{
${ }^{10}$ The distinction between knowledge and cognition is originally approached to in cultural anthropology. It is here conceived as an extension of the complementarity between process and state with regard to the idea of culture in terms of production and reproduction. Understanding both knowledge and cognition as characteristics of the human condition; we however distinguish between cognition as a process and knowledge as an accumulation or remaining trace of that process. Nonetheless the exclusive circumscription of the concept of cognition to the human being is biologically and anthropologically unsustainable, unless a link to exclusivity between the notions of cognition and knowledge is in turn established (i.e. cognition necessarily presupposes knowledge). As far as our proposition is concerned the distinctive idea of cognition (with regard to knowledge) finds close relationship with the Merleau-Pontian phenomology of perception.
} 
differentiated form of the general subject/world conception. Apart from this, given the constitutively socio-linguistic character of the subject, from now on we will understand the first pole of the subject-world pair in a purely acting sense, such as actor or agent. Its genetic link with the idea of subject makes it possible to conceive the 'subject' of cognition as proto-subject, precisely because it is a pure agent. The distance from the agent to the subject is the one that goes from the organism to the 'self'.

The centrality of observation both with respect to cognition and with respect to knowledge remains founded in a double conceptual link: the idea of cognition is articulated upon distinction; the idea of knowledge is articulated upon differential indication. In the context of cognition, the act of observation produces the observing subject as a pure agent. Observation takes the observer out of the world that he himself has produced by drawing an invisible metadistinction (which Spencer-Brown (1979, p. 62) names as 're-entry') and placing the difference beyond it. The world is thus the mark of the cognitive agent while the cognitive agent comes to be the trace of its own creating action. In order to reintroduce himself in the world, to be constituted into an objectivised-subject, the observer will need a mirror (self consciousness) and a conversation (society). In the case of the human being, both are possible because of and on the basis of language. The first characteristic of knowledge, the boundary of its distinction with regard to cognition, turns out to be thus the reintroduction of the observer in the world that emerges from observation, the production of subjects on the basis of the production of worlds.

The observing subject emerges as a fixed point (Dupuy, 1982) in the complementariety process among selfconsciousness, language and society that constitutes the antropocentred conception of knowledge. The processes of knowledge, therefore, will be characterised by the recursivity between the sides of distinction and, consequently, like two opposite mirrors, by the extension of differential logics in infinitely recursive chains.
That qualitative leap from cognition to knowledge, from the cognitive agent (protosubject) to the subject-observer, is only possible within the context of the sociolinguistic phenomenical domain. In Maturanian terms, the observer exists in language (Maturana, 1996, 148-149). According with that sociolinguistic foundational condition of observation it is possible to affirm with Maturana and Varela (1996) that "everything said is said by an observer to another observer".

More over, this implies supposing the genetically preceding condition of cognition regarding the distinction subject/object. Cognition involves the act of emergence of the world in a phenomenological sense close to the one proposed by Merleau-Ponty (1975) when focusing the body as the vehicle of being-in-the-world. For this reason, we have preferred to denominate the agent of cognition as proto-subject, precisely in the sense of a pure agent ontogenically involved in natural phenomena. In this sense organism (as a living system) is a precondition for the subject, but the latter does not circumscribe to the physical and organisational limits of the former ${ }^{11}$. Even more, through the concept of cognition understood as the organizational integration of the differences constituted from/in observation (Maturana and Varela, 1996), it is possible to reintegrate the world into the proto-subject: the cognitive agent constitutes a world in the act of cognition whose limits are the type of sensori-motor operations in which its operational closure is expressed. In

\footnotetext{
11 Morin (1997) focuses attention on the original biological features of subject: self-centrism, selfreference and self-finalism, all of these being organizational characteristics of the organism (or of the autopoietic unit as the Iving system). Consequently, the transition from proto-subject (the cognitive agent) to subject (the self-conscious self) is not merely a leap of ontological quality in the sense of producing a social subjectivity within the physical being. Subject is not a superposition over the organism in the same way that society is not a superposition over Nature. The relationship between organism (the cognitive protosubject) and subject (in its full sociolinguistic sense) is much more complex than an instrumental inclusion (as it is presupposed by the platonic tradition on the body/mind problem) or a corresponding inclusion (as proposed by a sort of contemporary biological humanism).
} 
terms of the authors mentioned (Ibid.), cognition, (and, by extension, also knowing) supposes the enaction ${ }^{12}$ of a world.

Subject and object are then constituted not strictly in cognition, but in the leap from cognition to knowledge. The subject emerges simultaneously upon the natural condition of the proto-subject and upon the social condition of the world enacted in language. In epistemological terms, that leap is decisive: from the world as a part of the proto-subject (cognitive agent) we come to the subject as part of the world. The subject is reintroduced into the world, and the world is distinguished through cognition by a differentiation which is possible upon the utterability of the world.

The observational conception of cognition/knowledge thus far sketched is based upon a principle of codetermination between form and structure which is necessarily coherent with the general implications of structural determination. The quantity of variety of a structure constrains the sphere of possibilities of transformation and interaction and consequently a given form refers to a possible spectrum of structures (and inversely). Form is therefore one of the possible traces of the action of the perceptive structure (understood as an operator of distinctions). Perceptive structure itself comes then to be a sort of formgenerating form.

If distinction and difference are the algorithmic conditions of form, then it can be argued that the implicit logic in the biocognitive conception of observation is a logic of form in the terms posed by Spencer-Brown (1979). Moreover, beyond the etymological play on words (in-formare is to put into form), this logic of form is also an informational logic in as much as information involves the 'act of giving form' inherent to distinction. And that idea of informational logic takes us to the matter of data as the atoms of observation. Neither logic of form nor informational logic allows us to conceive the data in a classic sense, as traces of the intrinsic characters of

\footnotetext{
${ }^{12}$ The term 'enaction' was coined by Varela (1979; 1996) to designate precisely the idea of cognition as the act of bringing forth the world in operational coherence with the cognitive agent. From the enactive perspective, knowing is the action of making a world emerge.
}

the object. If we accept the relationship between observation and cognition/knowledge as informational, then observation cannot constitute a sort of affidavit on the object, but rather a recursive coordinated production of coordinated differences.

From this perspective communication cannot be understood as a process of transmission or as a purely referential action. Firstly, because information, as an endogenous distinction coherent with the structure of the system, is in no way transmissible. Secondly, communication, as relative to observational behaviour, can be constituted as relating to a meaning only in the terms of a semantic description ${ }^{13}$ operated by the observer: the meaning of a communication lies in its cognitive nature of selective action and consequently it is a product of the relational distinction operated by the observer with respect to a unit and its environment.

Conversely, the idea of communication in the observational perspective refers to a process of coordination of operational coherences, i.e. as the realization of those behavioural coordinations which constitute (and become a constitution of) society. Luhmann (1991, p. 204) uses the term interpenetration to refer precisely to that process through which cognitive processes are interlaced in ontogenetic co-dependence. Precisely, the German sociologist points to communication as the kind of operation which makes possible the organizational

\footnotetext{
13 A semantic description, according to the terminology used by Maturana and Varela (1996, p. 178 ), is precisely the type of relational distinction operated by the observer in reference to an interaction that gives rise to the generic concept of behaviour. In other words, a semantic description is a projection of the observer that imposes meaning over phenomena. The confusion of the properties emanated from the semantic description with the organisational properties of the observed phenomenon makes it possible for example to define communication as the "transference" of information or meanings between subjects. In this same sense it is the quality of semantic descriptability what makes it possible to deal with the domain of communicative behaviour as a domain of coordinated behaviours associated to semantic terms. In Varela's terms, the semantic description only transcends the linguistic domain to the extent that this is overlapped to the cognitive and existential domains.
} 
closure of the social system, i.e. the social system's autopoetic operation (the operation via which the system produces the networks of operations that constitute it). Communication, Luhmann concludes, is the social system's operation of the recursive distinction (the re-entry of the distinctionindication between system and environment).

Communication thus involves a relational dimension superimposed on the cognitive process understood as a management of differences. The incommunicability of endogenous information upon which cognition is constructed is solved by the selfreferential coupling between selection (or observation) processes. The same argument by von Foerster (1991) quoted above with regard to the principle of relativity (see footnote 7) is useful for illustrating communication as a double contingency process between observable systems (Luhmann, 1991, p. 202). The mutual contingency between observable systems is a logical requirement derived from its own self-reflexive operation. Using Luhmann's terminology, the leap from cognition to knowledge is possible within the linguistic domain as a double contingency between ego and alter from which both emerge as subjects.

The characterization of communication as interpenetration or double contingency constitutes the essential reason for which Luhmann (1991, p. 140) defines it as an exclusively social phenomenon beyond the unavoidably self-referential condition of the subjects of cognition -"only social systems can communicate" (Luhmann, 1991, p. 142). That seems to be the final reason why, for Maturana and Varela (1996, p. 144), language as the sphere of "consensual coordination of interactions" constitutes a domain that is superimposed over cognitive and existential domains. Communication in that sense becomes the processing form of social system's (self-)observation through which subjects reflexively transcend the limits of cognition.

\section{References}

Aguado, J.M. (2000). "El Golem y el jugador de ajedrez: La IA como mitología de la Naturaleza". Sphera Publica. Revista de Ciencias Sociales, 1(0), 111-117.

- "Making the social subject: the role of theory and technology in social emergence". Journal of Sociocybernetics, 2/1, pp. 2-9

- (2003). Comunicación y Cognición. Las bases de la complejidad. Sevilla, Comunicación Social Ediciones.

Ashby, W.R. (1977). Introducción a la cibernética. México. Ediapsa.

Atlan, H. (1990). Entre el cristal y el humo. Madrid. Debate.

Bateson, G. (1985). Pasos hacia una ecología de la mente. Buenos Aires. Carlos Lohé.

- (1991). Sacred Unity: Further Steps to an Ecology of Mind. New York. E.P. Dutton.

Brillouin, L. (1956). Science and Information Theory. New York. Academic Press.

Brier, S. (1992). "Information and Consciousness: A Critique of the Mechanistic Concept of Information". In Cybernetics \& Human Knowing, 1(1-2), 7-29.

Crosson, F.J. and Sayre, K.M. (1971), Cibernética y Filosofía. México. F.C.E.

Dupuy, J. P. (1994). Aux origines des sciences cognitives. Paris. La Découverte.

Foerster, H. von (1960). Self-organizing systems. California. Yovitz and Cameron.

- (1981). Observing systems. Seaside, California. Intersystems Publications.

- (1991). Las semillas de la cibernética. Barcelona. Gedisa.

Fuller, S. (1988). Social Epistemology. Bloomington. Indiana University Press.

Hacking, I. (1995). La domesticación del azar. Barcelona. Gedisa.

- (1996). Representar e intervenir. Barcelona. Paidós.

Ibáñez, J. (1985). Del algoritmo al sujeto. Perspectivas de la investigación social. Madrid. Siglo XXI.

Ibáñez, J. (1994). El regreso del sujeto. La investigación social de segundo orden. Madrid. Siglo XXI.

Iranzo, J.M. and Blanco, J.R. (1999). Sociología del conocimiento científico. Madrid. CIS-Universidad de Navarra.

Johnson, M. (1991). El cuerpo en la mente. Fundamentos corporales del significado, la imaginación y la razón. Madrid. Debate.

Kant, E. (1970). Crítica de la razón pura. Madrid. Ediciones Ibéricas.

Kauffman, S. (1993). The Origins of Order: Self-Organization and Selection in Evolution. Oxford University Press.

Luhmann, N. (1982). The differentiation of society. New York. Columbia University Press.

- (1989). Ecological Communication. Cambridge. Polity Press.

- (1990a). Essays on self-reference. New York. Columbia University Press.

- (1990b). "The Cognitive Program of Constructivism and a Reality that Remains Unknown". In Krohn, W.; Günther, K. \& Nowotny, H. (1990). Self-organization: Portrait of a Scientific Revolution. Boston. Kluwer Academic Publishers.

- (1991). Sistemas sociales: lineamientos para una teoría general. Barcelona. Anthropos. 
- (1996). La Ciencia de la Sociedad. México. Universidad Iberoamericana.

- (1997). Organización y decision: autopoiesis, acción y entendimiento comunicativo. Barcelona. Anthropos.

Maruyama, M. (1961). "Communicational epistemology". British Journal for the Philosophy of Science. 11(44)

- (1990). Biología y epistemología de la cognición. Santiago de Chile. Universidad de la Frontera.

- (1995). La realidad: ¿objetiva o construida ?. I. Fundamentos biológicos de la realidad. México. Universidad Iberoamericana.

- (1996). La realidad: ¿objetiva o construida ?. II. Fundamentos biológicos del conocimiento. México. Universidad lberoamericana.

Maturana, H. and Varela, F. (1980). Autopoiesis and cognition: the realization of the living. Dordrecht. Reidel.

Maturana, H. and Varela, F. (1996). El árbol del conocimiento. Las bases biológicas del conocimiento humano. Madrid. Debate.

Mead, G.H. (1972). Espíritu, persona y sociedad. Barcelona. Paidós.

Merleau-Ponty, M. (1975). Fenomenología de la percepción. Barcelona. Península.

Morin, E. (1992). El método IV. Las Ideas. Madrid. Cátedra.

- (1993). El método I. La naturaleza de la Naturaleza. Madrid. Cátedra.

- (1994). El método III. El conocimiento del conocimiento. Madrid. Cátedra.

- (1997). El método II. La vida de la vida. Madrid. Cátedra.

Nowotny, H. (1990). "Self-organization: the Convergente of Ideas. An introduction". In Krohn, W.; Günther, K. \& Nowotny, H. (1990): Self-organization: Portrait of a Scientific Revolution. Boston. Kluwer Academic Publishers.

Piaget, J. (1969). Biología y conocimiento. Ensayo sobre las relaciones entre las regulaciones orgánicas y los procesos cognoscitivos. México. Siglo XXI.

- (1983). Estudios sociológicos. Barcelona. Ariel.

- (1986). La epistemología genética. Madrid. Debate.

Priest, S. (1994). Teorías y filosofías de la mente. Madrid. Cátedra.

Putnam, H. (1988a). Las mil caras del realismo. Madrid. Paidós.

- (1988b). Razón, verdad e historia. Madrid. Tecnos.

- (1994). Cómo renovar la filosofía. Madrid. Cátedra.

Qvortrup, L. (1993). "The Controversy over the Concept of Information". In Cybernetics \& Human Knowing, 1(4), 42-66.

Rorty, R. (1983). La Filosofía y el espejo de la Naturaleza. Madrid. Cátedra.

Ross Anders, A. (Ed.) (1984). Controversia sobre mentes y máquinas. Barcelona. Tusquets.

Schuster, F. (1996). El escenario posempirista en la ciencias sociales de fin de siglo. Buenos Aires. Mimeo.

Schutz, A., and Luckmann, Th. (1973). Estructuras del mundo de la vida. Buenos Aires. Amorrortu.

Segal, L. (1994). Soñar la realidad. El constructivismo de Heinz von Foerster. Barcelona. Paidós.

Serres, M. (1972). Hermes II: L'interférence. Paris. Editions de Minuit.

- (1991). El paso del Noroeste. Madrid. Debate.

- (1995). Atlas. Madrid. Cátedra.

Shannon, C.E. (1972). "Information Theory". Encyclopedia Britannica, vol. 12. Chicago et al.

Shannon, C.E. \& Weaver, W. (1949). The Mathematical Theory of Communication. Urbana. Illinois University Press.

Spencer-Brown, G. (1957). Probability and Scientific Inference. London. Longmans, Green \& Co.

Spencer-Brown, G. (1979). Laws of form. New York. E. P. Dutton.

Stonier, T. (1990). Information and the Internal Structure of Universe. London. Springer Verlag.

Varela, F. (1979). Principles of biological autonomy. London. Elsevier.

- (1996). Conocer. Las ciencias cognitivas: tendencias y perspectivas. Cartografía de las ideas actuales. Barcelona.

Gedisa.

Varela, F., and Dupuy, J.P. (1992). Understanding Origins. Contemporary Views on the Origin of Life, Mind and Society, London. Kluwer Academic Publishers.

Varela, F., Thompson, F., and Rosch, E. (1997). De cuerpo presente. Las ciencias cognitivas y la experiencia humana. Barcelona. Gedisa.

Watzlawick, P. and Krieg, P. (Eds.) (1994). El ojo del observador. Contribuciones al constructivismo. Homenaje a Heinz von Foerster. Barcelona, Gedisa

Wiener, N. (1954). The Human Use of Human Beings: Cybernetics and Society. New York. Avon.

\section{About the Author}

Juan Miguel Aguado

$\mathrm{PhD}$ in Communication Studies at the Complutense University of Madrid (Spain) and Postgraduate Degree in Phylosophy and Sociology at the Polish Academy of Sciences (Warsaw). He is member of the Research Committee on Sociology of Communication, Culture and Knowledge (RC14) and the Research Committee on Sociocybernetics at the International Sociological Association (ISA). Actually he is Associate Professor of Communication Theory in the School of Communication and Information Studies at the University of Murcia (Spain). His research and publications focus on epistemology of communication, complexity and constructivism as well as on the social impact of technology, mobility and the role of experiential mediation in cultural consumption processes. 